\title{
El servicio de ayuda a domicilio en el área metropolitana de Valencia
}

\section{Óscar Muñoz González}

Facultad de Ciencias Sociales, Universidad de Valencia

oscar.munoz@uv.es

\section{Josep V. Pitxer i Campos}

Departamento de Economía Aplicada, Universidad de Valencia

Josep.V.Pitxer@valencia.edu

\begin{abstract}
Valentziako metropolialdeko etxez etxeko laguntzazerbitzuaren zenbait alderdi aztertzen dira artikulu honetan. Izaera kualitatiboa duen metodologia ardatz gisara hartuz, literatura espezializatua eta testu juridikoak berrikusi dira, eta horretaz gain, hogeita bederatzi elkarrizketa sakon burutu dira. Horiek oinarri hartuz, ondorio gisara azaltzen da tokiko korporazioek sistema publiko baten eta erakunde pribatuen arteko hautua egin dezaketela. Halaber, erabiltzaileekin lan egiten duten laguntzaileen jarduerak praktikan erabat berberak direla egiaztatzen da, dena dela aztertutako udalerria edota prestazio mota. Azkenik, prestazioa kanpoko erakunde pribatu batek ematen duenaren aldean, etxez etxeko laguntza-zerbitzuetako langileen laneko baldintzak hobeak omen dira hornitzailea publikoa den kasuetan.
\end{abstract}

\section{GAKO-HITZAK:}

Etxez etxeko laguntza-zerbitzua, zaintza, zaintzalanak, zaintzen hornidura, profesionalizazioa.
En este artículo se analizan algunos aspectos del servicio de ayuda a domicilio en el área metropolitana de Valencia. A partir de una metodología cualitativa, con la revisión de literatura especializada y de textos jurídicos, y con la realización de veintinueve entrevistas en profundidad, se concluye que las corporaciones locales disponen de suficiente autonomía para elegir o un sistema público o bien su externalización a favor de organizaciones privadas. Igualmente, queda acreditado que las actividades desarrolladas por las auxiliares de ayuda a domicilio en pro de los usuarios son prácticamente idénticas independientemente del municipio que se estudie y del tipo de prestación, y, por último, se corrobora que las condiciones laborales de las auxiliares de ayuda a domicilio son mejores en los casos de servicios de provisión pública que en los de prestación externalizada privada.

\section{Palabras Clave:}

Servicio de ayuda a domicilio, cuidados, trabajo de cuidados, provisión de cuidados, profesionalización. 


\section{Introducción}

Se hace cada vez más patente la necesidad de provisión de cuidados a las personas mayores o en situación de dependencia en la sociedad actual. Nos hallamos ante un cúmulo de factores de diversa índole-demográficos, sociales, económicos, culturales- que han originado un desajuste en los cuidados y que empujan a la búsqueda de soluciones ante el nuevo panorama. De entre los espacios en los que se pueden llevar a cabo la prestación de los cuidados nos encontramos con el doméstico-familiar, esto es, los efectuados en el seno del hogar, tarea que ha sido tradicionalmente llevada a cabo por las mujeres de forma invisibilizada y no remunerada. Junto a los cuidados familiares nos encontramos con la posibilidad de su externalización/mercantilización, ejecutándose dentro del mismo hogar, una vía correctora de los desajustes en los cuidados. Así, en el supuesto mercantilizado encontramos, por un lado, los cuidados remunerados en el ámbito del hogar, donde la persona mayor o dependiente (o su familia) contrata a una persona, por regla general mujer de procedencia latinoamericana (Martínez Buján, 2010), sin que exista organización de por medio, y que generalmente se engloba dentro de la economía informal (Martínez Buján y Martínez Virto, 2015: 196). Otra alternativa de externalización mercantil tiene lugar cuando el núcleo familiar decide contratar los servicios de ayuda a domicilio a una organización, con o sin ánimo de lucro. Para finalizar, otra opción son los cuidados provistos por la misma Administración Pública dentro del ámbito doméstico. Hablamos, pues, del conocido como Servicio de Ayuda a Domicilio municipal (en adelante, SAD), englobado dentro de los servicios sociales generales, que es, a la par, un servicio de proximidad (Parella, 2003), y que forma parte de los diecisiete nuevos yacimientos de empleo (Torns 2014: 8). No obstante, este servicio, aun siendo de titularidad pública, no conlleva implícitamente que su prestación también lo sea. De hecho, caben diferentes opciones a este respecto: o bien que corresponda a la Administración, sea con personal propio o contratado, sea a través de una empresa pública, o bien que la Administración lo externalice y sea prestado por una organización, con o sin afán lucrativo.

Por otro lado, y como añadidura, hay que prestar la atención oportuna a la Ley de la Dependencia, ley que reconoce un derecho subjetivo a la ciudadanía y que ofrece un catálogo en el que figura el SAD como tal, así como la prestación económica vinculada al servicio, con la que se dota de una cantidad pecuniaria al beneficiario para que contrate los servicios de ayuda a domicilio a una organización privada. Estamos, por tanto, ante un servicio autonómico paralelo al prestado por las corporaciones locales.

Con lo dicho, en este texto vamos a centrarnos en el SAD en el área metropolitana de Valencia (en adelante, AMV), marcándonos como principales objetivos los siguientes:
- Comprobar cuál es el procedimiento que siguen los servicios sociales de cada entidad local a la hora de otorgar el servicio objeto de estudio.

- Determinar qué sistema de prestación ha escogido cada municipio y obtener una valoración sobre las ventajas y desventajas en relación con que su prestación sea pública o privada.

- Conocer cuáles son las principales actividades que se prestan en el SAD por los/las auxiliares de ayuda a domicilio.

- Establecer los principales obstáculos que les surgen a los operadores privados prestadores del SAD.

- Explorar el quehacer diario y las condiciones laborales de las auxiliares de ayuda a domicilio.

- Obtener la visión que tiene la sociedad sobre este servicio y sobre el trabajo desempeñado por las auxiliares de ayuda a domicilio a partir del relato de las personas entrevistadas.

Todos estos objetivos vienen acompañados de la hipótesis de que los municipios gozan de suficiente autonomía para decidir qué sistema prestatario adoptan, encontrándonos con una variedad de estos dentro del territorio objeto de análisis. Por otra parte, hay un común denominador en cuanto a las actividades que se acaban prestando por las auxiliares de ayuda a domicilio y el tiempo del que disponen para realizar su trabajo. A esta hipótesis se suma que la elección del sistema (público o externalizado) tiene consecuencias en su dimensión laboral, presumiendo que hay mejores condiciones cuando la prestación es pública.

La revisión de bibliografía especializada y textos jurídicos, junto a la realización de entrevistas en profundidad, fueron los soportes metodológicos para la realización de este trabajo. Se efectuaron veintinueve entrevistas en profundidad semiestructuradas: diez trabajadores/as sociales de algunos municipios del $A M{ }^{1}$, encargados del control y supervisión (y en algunos casos la coordinación) del SAD municipal; dos representantes de la patronal (Aerte); tres representantes de los sindicatos más representativos (uno de CCOO-Pais Valencià y dos de UGT-Pais Valencià); dos fundadores de la primera organización prestadora del SAD en el municipio de Valencia (una cooperativa); cuatro responsables de entidades prestadoras del SAD en dicha área; y ocho auxiliares de ayuda a domicilio, tanto municipales como de empresas externalizadas, todas ellas mujeres. Las entrevistas fueron grabadas en audio para su posterior transcripción, garantizando el anonimato y la confidencialidad. Este trabajo se realizó en el periodo comprendido entre octubre del 2016 y abril del 2017.

${ }^{1}$ Los municipios analizados han sido Alaquàs, Albal, Alboraia, Benetússer, Godella, Mislata, Paterna, Rocafort, Tavernes Blanques y Valencia. 
Desgraciadamente, no fue posible contar con la participación de auxiliares de ayuda a domicilio que desarrollasen su labor en empresas públicas, careciendo así del conocimiento acerca de sus condiciones laborales. Del mismo modo, se trató de conseguir una mayor participación de empresas prestadoras del SAD en el AMV, sin embargo, declinaron la invitación, quedando finalmente cuatro empresas dispuestas a colaborar.

Junto a esta introducción, el texto se estructura en un marco teórico donde se aborda qué son los cuidados, qué es el trabajo de cuidados y las diferentes esferas de prestación. Le sigue una breve exposición sobre el SAD y sus antecedentes históricos. Tras este bloque se aborda la parte empírica, donde figuran los resultados obtenidos a partir del trabajo de campo. Finaliza con el apartado de conclusiones.

\section{Marco teórico}

\subsection{Qué son los cuidados}

En las últimas décadas han proliferado los estudios sobre los cuidados desde diferentes disciplinas. Se han convertido en objeto de análisis, aunque lo cierto es que siguen siendo, hoy día, un concepto poliédrico y con dificultades para dotarle de contenido (Martín Palomo, 2008b, 2016: 31; Carrasquer, 2013: 105; Torns (dir.) et al., 2014: 13; Roca, 2017: 377). Un primer problema que presenta el uso del término care es su difícil traducción a otras lenguas, como la castellana; no en vano, hay un doble significado en inglés, ya sea caring for - cuidar de alguien, en el sentido de trabajo- o caring about -apreciar a alguien, en el sentido de afecto, de preocupación(Leira, 1994: 187; Martínez Buján, 2010: 54). Por otro lado, hasta las ideas ilustradas y liberales no tiene lugar una dicotomía clara entre el trabajo productivo y el reproductivo. A partir del contrato social de la época es cuando queda sellada la división entre las esferas pública y privada, asociando al hombre en la primera y a la mujer en la segunda, como ama de casa-cuidadora (Marugán, 2014: 2016), y que da pie a desvirtuar el valor del trabajo doméstico (Cerri y Alamillo-Martínez, 2012) y del trabajo reproductivo (Comas d'Argemir, 2015: 377). Esto también se hace patente con la división sexual del trabajo en la etapa de la industrialización del siglo XIX (Comas d'Argemir, 1995: 50-51; Martín Palomo, 2014: 113), y tras la II Guerra Mundial y el desarrollo de los Estados del Bienestar, con el modelo malebread-winner/ housewife-keeper (Ezquerra, 2011: 178).

Ya en el siglo XX los cuidados fueron estudiados dentro de los trabajos relacionados con el trabajo doméstico, punto de anclaje para el posterior estudio sobre la materia aquí tratada. En los años ochenta, y desde el feminismo británico (Torns 2014: 13-14) dos obras parecen ser las pioneras sobre los cuidados. Por una parte, la obra de Finch y Groves, A labour of love: women, work and caring; por otra, la de Carol Gilligan, In a different voice (Graham,
1991: 64; Martín Palomo 2008a: 30). Todo ello sin restar valor a las aportaciones previas de sociólogas italianas y su concepto de lavoro de cura (Carrasco, Borderías y Torns, 2011: 32-33) o de las especialistas escandinavas. Por un lado, la obra de Finch y Groves se circunscribe al trabajo no remunerado en el ámbito doméstico-familiar (Daly y Lewis, 2000: 83). Del mismo modo, Hilary Graham, en el capítulo "Caring: a labour of love", incluido en la obra de Finch y Groves, presenta los cuidados como trabajo y como amor, una relación situada en el seno de la familia, no remunerada, ejecutada por el colectivo femenino y vista como característica innata/natural por su condición de mujer (Graham, 1983; Thomas, [1993]2011: 158; Carrasquer, 2013: 97; de São, 2016: 61). Sin embargo, y como recoge Thomas ([1993] 2011), otras, como Roy Parker, fijan su atención en la persona receptora de cuidados, personas en situación de dependencia.

Por su parte, Ungerson (2005, entre otros), considera que el cuidado puede ser provisto por personas ajenas a la familia, tales como el personal sociosanitario, de forma remunerada, y no por ello ser cuidados de peor calidad. De hecho, la literatura científica escandinava pone el foco en los cuidados formales, en los cuidados como trabajo, y en su organización social, posiblemente por su propio Estado del Bienestar, más desarrollado en servicios sociales y con atención especial a los cuidados (Leira, 1994: 186)². En los años noventa, y gracias a las aportaciones de las teorías feministas críticas, se reformuló/revisó el concepto de cuidados, y a partir de entonces se incluyeron otros aspectos a analizar, como las condiciones laborales de las cuidadoras, los cuidados realizados por hombres, por no familiares, etc. (de São, 2016: 62). Muchas otras científicas sociales han abordado la temática de los cuidados, y en el ámbito nacional destacamos a María Teresa Martín Palomo, Raquel Martínez Buján, Teresa Torns, Cristina Carrasco, Amaia Pérez Orozco o Dolors Comas d'Argemir.

Entrando ya en la definición, una de las menos restringidas sobre qué son los cuidados es la realizada por Berenice Fisher y Jean Tronto, que los definen como
"Una actividad de especie que incluye todo aquello que hacemos para mantener, continuar y reparar nuestro "mundo" de tal forma que podamos vivir en él lo mejor posible. Ese mundo incluye nuestros cuerpos, nuestros seres y nuestro entorno, todo lo cual buscamos para entretejerlo en una red compleja que sustenta la vida" (Tronto, 2004, en Fisher y Tronto 1990).

Quizá, y por su funcionalidad, destaca la aportación de Carol Thomas ([1993]2011), que descompone los cuidados en varias dimensiones:

${ }^{2}$ Como subrayan Torns etal. (2014:14), "las feministas británicas criticaron la propuesta escandinava porque al reducir los cuidados a trabajo se perdía, desde su punto de vista, la dimensión emocional de los mismos". 
- La identidad social de la persona cuidadora, refiriéndose a las características sociales definitorias de una persona como cuidadora (madre, esposa, enfermera, etc.),

- La identidad social de la persona receptora de cuidados, en general, una persona en situación de dependencia,

- Las relaciones interpersonales entre las dos anteriores, ya sea por vínculos familiares, por amistad, o por vecindad.

- La naturaleza de los cuidados, en el sentido de si se trata de una actividad en cuanto tarea, o va más allá, incorporando elementos afectivo-emocionales.

- El “lugar” o esfera donde se efectúan los cuidados (privado o público).

- El carácter económico de los cuidados: remunerado o no remunerado.

- El marco institucional en el que se prestan, la localización física (el domicilio, un centro de día, una residencia).

Y a partir de estas dimensiones, conceptualiza los cuidados como:

“La prestación remunerada o no remunerada de apoyo en la cual intervienen actividades que implican un trabajo y estados afectivos. Los prestan principal, aunque no exclusivamente, mujeres, tanto a personas adultas sanas como a personas dependientes y a los niños y niñas, en la esfera pública o en la esfera doméstica, y en una diversidad de marcos institucionales" (Thomas, ([1993]2011: 169).

Siguiendo a autoras como Comas dœArgemir (1993: 67; 1995: 129; 2016: 11), Knijn y Kremer (1997: 330), Pérez Orozco (2014: 92) o Lina Gálvez (2016: 19), entendemos los cuidados como aquellas necesidades de las personas que deben ser cubiertas para la garantía de su bienestar físico, psíquico y emocional.

\subsection{Qué es el trabajo de cuidados}

A las dificultades para conceptualizar qué son los cuidados hay que sumarle la problemática en torno a qué es el trabajo de cuidados. En este artículo se tomará como referencia un concepto amplio de trabajo para su comprensión, entendiéndolo como:

"El esfuerzo humano que realiza una persona para producir bienes y servicios con el fin de $\mathrm{s}$ atisfacer unas necesidades, dentro de unos contextos sociales concretos y específicos [...], convirtiéndose en un marco clave para la comprensión de los fenómenos laborales" (Muñoz y Pitxer, 2016a: 105).

Dentro del trabajo diferenciamos dos tipologías: el trabajo productivo o mercantil y el trabajo reproductivo. El primero es el trabajo en el que existe una remuneración o contraprestación económica al trabajador por el desempeño de las tareas asignadas por el empleador. De hecho, este concepto de trabajo es el hegemónico para la comprensión de qué es el trabajo y es el asociado al término empleo. Mientras, el trabajo reproductivo es aquél que no está salarizado, cuyas actividades son consideradas como "infraeconómicas (Martínez Veiga, 1995: 14), invisibilizadas y con escasa valoración social (Comas d'Argemir, 1995). El debate sobre el trabajo doméstico de los años sesenta y setenta (Martín Palomo, 2016: 51-58) empuja a que se hagan esfuerzos para incorporar estas actividades reproductivas dentro del término trabajo, para seguir en la década de los ochenta, en la que se afirma que no pueden entenderse el uno sin el otro, ya que el reproductivo garantiza la existencia del productivo (Muñoz y Pitxer, 2016a; Ezquerra, 2018). En cuanto a qué actividades quedan enmarcadas dentro del trabajo reproductivo, según Carrasquer et al. (1998: 102) hay varias dimensiones incluidas en él, entre las que destacan las tareas de infraestructuras, las de organización o las reproductoras. Dentro de las de infraestructuras hallamos actividades como la limpieza del hogar, de la ropa, preparar el desayuno, la comida o la cena, o la compra; dentro de las organizativas, veríamos actividades tales como la administración de la casa; y dentro de las relativas a las cargas reproductoras, algunas como la atención a los hijos, a personas mayores o a enfermos. Por tanto, el trabajo de cuidados es difícil que pueda argumentarse sin tener en consideración previa estas actividades incardinadas dentro del trabajo reproductivo. Por su parte, Cristina Carrasco (2003), apunta a que el trabajo de cuidados tiene un contexto diferente que el remunerado y que "satisface necesidades personales y sociales que no permiten una simple sustitución con producción de mercado". De ahí que deba aunarse un componente afectivo que, a la par, sustenta a la sociedad y a la economía productiva. Una propuesta innovadora es la referente a la domesticación del trabajo (Martín Palomo, 2008a), que trata de superar la visión tradicional del trabajo como eje vertebrador del individuo y que trasciende la mirada del trabajo propia de la norma social (asalariado, obrero industrial, etc.). Su pretensión es que a la dimensión material, a las actividades propias del trabajo de cuidados, se le incorporen dos dimensiones más: la emocional, en tanto que entran en juego los aspectos afectivos en el cuidado de otra persona, y la moral, en el sentido de responsabilidad sobre el acto de cuidar. Pero, en cualquier caso, sin olvidar que el cuidado es un trabajo.

Por tanto, entenderíamos que el trabajo de cuidados es esa actividad desempeñada por las personas cuidadoras cuyo fin es la satisfacción de las necesidades humanas que garanticen el bienestar material, físico, psíquico y emocional de las personas receptoras de cuidados, con la posibilidad de que exista o no contraprestación económica, donde participan actores como la familia, el Estado, el mercado o la sociedad civil -sin ser excluyentes 
entre sí-, que incluye tareas o actividades concretas, que contienen un aspecto relacional, y que van acompañadas o no de un componente afectivo-emocional.

\subsection{Los diferentes actores en la provisión de los cuidados: el diamante de cuidados}

\subsubsection{El papel del Estado en la cuestión}

El Estado del Bienestar, los estudios de género y las políticas sociales entran en juego en el debate acerca de los cuidados. El Estado del Bienestar se había construido con ceguera en relación al género, de ahí las voluntades para incluirlo, dando lugar a los gender regimes. Lo mismo sucede con la incorporación de los cuidados a dichos regímenes del Estado del Bienestar, que, a su vez, hacen emerger los care regimes. Por su parte, las políticas sociales, esto es, la acción pública del Estado en la provisión de los cuidados, también aparecen en escena, y diversas científicas sociales (Ungerson, Antonnen, Sipila, Lewis, etc.) han venido desarrollando sus trabajos sobre esta materia. La institucionalización del denominado social care u organización social de los cuidados tiene lugar con la obra de Daly y Lewis (2000: 285), que lo definen tanto por ser actividades como por las relaciones presentes destinadas a satisfacer las necesidades de adultos y niños en situación de dependencia, enmarcado todo ello en unos contextos normativos, económicos y sociales. Sus ideas-fuerza se centran en la división de agentes provisores de cuidados, como son el Estado, la familia, el mercado y la sociedad civil/comunidad, y cómo en cada uno de los regímenes del Estado del Bienestar se tiende a hacer recaer el peso de los cuidados de forma mayoritaria sobre alguno de estos agentes. Por ejemplo, en los países escandinavos hay una actuación destacada del Estado en la provisión de los cuidados, mientras que en los países del Estado del Bienestar mediterráneo, estos descansan mayoritariamente en la familia (Bettio y Plantenga,
2004; Tobio et al. 2010: 139; Peterson, 2015: 223; Díaz y Elizalde, 2015: 132) y en la población inmigrante (Bettio, Simonazzi y Villa, 2006). España, dentro del bloque de los regímenes de Estado del Bienestar mediterráneo, destaca por ser un sistema familiarista, donde goza de un peso considerable la familia en la provisión de los cuidados, al tiempo que hay un escaso desarrollo de los servicios sociales (Recio et al. 2015: 180; Muñoz y Pitxer, 2016b: 70), situación que se retroalimenta. Vemos, entonces, que el contexto y los aspectos culturales son elementos a tener en consideración a la hora de analizar los regímenes de cuidados. Se formaría, pues, el denominado diamante de cuidados, al que hace referencia Razavi (2007: 21), cuya arquitectura quedaría conformada como se muestra en la Figura 1.

\section{Algunos apuntes sobre el Servicio de Ayuda a Domicilio}

\subsection{Antecedentes del Servicio de Ayuda a Domicilio}

Aun cuando los servicios de atención domiciliaria en el Estado español pueden remontarse a tiempos lejanos (García-Maestro, 2013: 331-332), los antecedentes se encontrarían en las actividades caritativas de algunas instituciones religiosas, cofradías y gremios. Ya hay muestras de esta actividad caritativa en los siglos XIII o XIV, aunque estas actuaciones estaban dirigidas a colectivos muy concretos: pobres y mendigos. En el siglo $\mathrm{XVI}$, y dirigido a los pobres vergonzantes - pobres sobrevenidos y a los que avergonzaba pedir en la calle- (Maza, 1987: 25; Alonso y Gonzalo, 200: 73; García Maestro, 2013: 332) se les asistía mediantes los socorros domiciliarios en algunas parroquias de la villa de Madrid. La Ilustración y el liberalismo (siglos XVIII-XIX) desempeñan un papel determinante para situar en un segundo plano la caridad cristiana y adentrarse en un sistema de beneficencia (López, 2010). En el siglo XVIII, Carlos III estableció que las

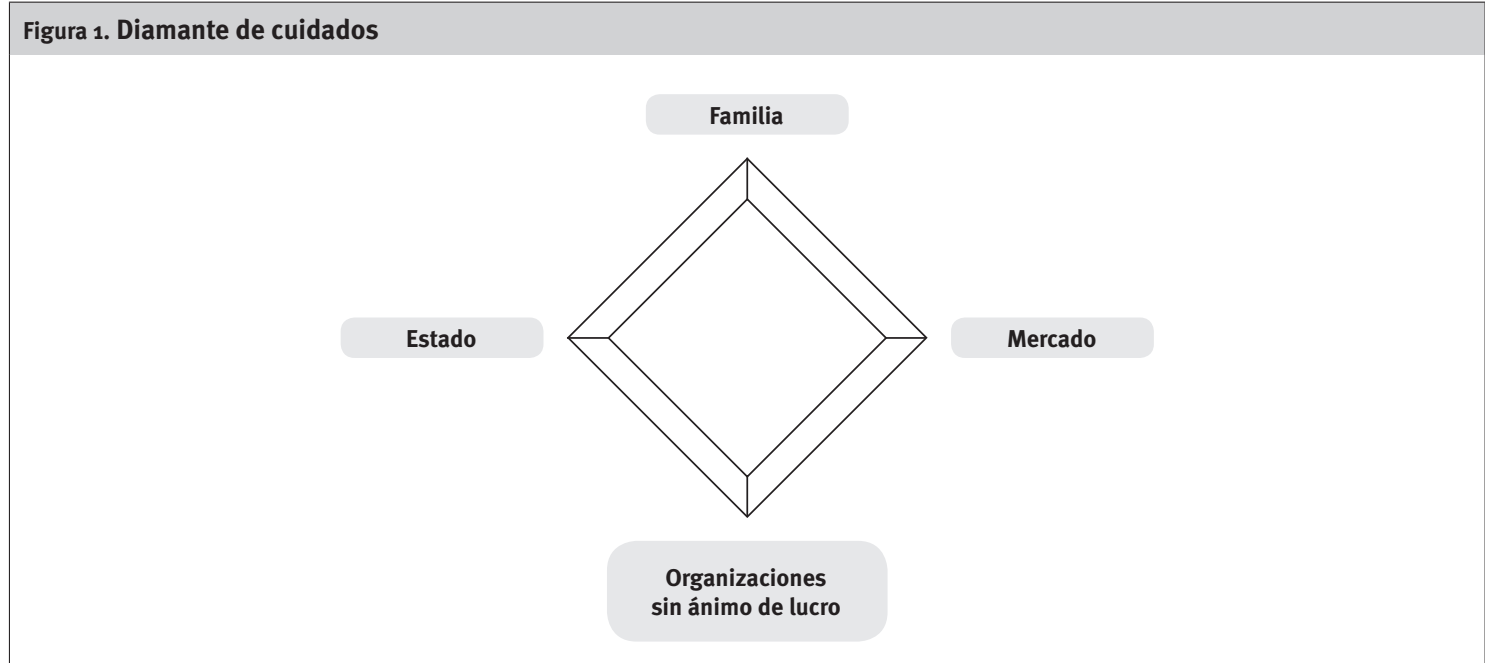

Fuente: Razavi, 2007: 21. 
juntas de barrio, y posteriormente las juntas de caridad, se encargasen de tales fines, aunque se tratase de una actuación de "profilaxis de pobres" (Maza, 1987: 53). Es durante este reinado cuando se dan muestras de las primeras señales del paso de la caridad a la beneficencia.

La beneficencia aparece recogida en la Constitución liberal de 1812, en sus artículos 321.5 y 335.8. Con Fernando VII, en 1816, se firma el Reglamento de hospitalidad domiciliaria. En este sentido, y pese a ser un rey absolutista, contrario y perseguidor de las ideas liberales, lo cierto es que, como señala Florentina Vidal (1987: 45) “el plan de Beneficencia promocionado por Fernando VII en 1816 permite pensar que existió una toma de conciencia por parte de la clase dirigente de los problemas de los necesitados".

En 1822, durante el Trienio Liberal, se aprueba la Ley sobre Establecimiento general de Beneficencia, donde se recogen tanto los denominados socorros domiciliarios ${ }^{3}$, como la hospitalidad domiciliaria ${ }^{4}$, ambas bajo responsabilidad de los ayuntamientos. Sancionada esta ley, la beneficencia pasaba a estar bajo el mando de la Administración como un servicio público. Sin embargo, la ley no pudo aplicarse: con la década absolutista se abole y marca un punto de retorno al sistema caritativo de antaño.

En 1949 se aprueba la segunda ley de beneficencia, que en su artículo 13 dice que "las Juntas municipales organizarán y fomentarán todo género de socorros domiciliarios y muy particularmente los socorros en especie". Esta ley fue desarrollada en el reglamento de 1852 , norma en la que se establece que los socorros y la hospitalidad domiciliaria son la más importante obligación en materia de beneficencia (artículo 90).

No obstante, todas estas ideas acerca del papel que estaba adoptando el Estado y la visión o principios sobre los que se sustentaban fueron contestadas por los movimientos obreros, al considerar que estaban recibiendo por caridad algo que les correspondía por justicia. Desde mediados del siglo XIX, la situación de pauperización de la población fue en aumento y como consecuencia de las presiones populares (Buj, 19915; De la Calle, 1984; Sánchez, 2014), se decidió crear la Comisión de Reformas Sociales en 1883. Hablamos, pues, de la denominada "cuestión social",

${ }^{3}$ Sirva como referencia el artículo 21, en el que se establece que “Las Juntas Parroquiales cuidarán de [...] los socorros domiciliarios [...] y de conducir a los establecimientos de Beneficencia respectivos a los que no puedan ser socorridos en sus propias casas". 0 el artículo 40, que dice así: "Los objetos que han de estar bajo la dirección y vigilancia de las Juntas municipales de Beneficencia son [...] la hospitalidad y los socorros domiciliarios". El título V de la citada ley está dedicado a los "Socorros domiciliarios", y el título VI a la hospitalidad domiciliaria.

${ }^{4}$ Antes de Fernando VII, su abuelo, Carlos III ya puso en funcionamiento un plan de beneficencia, que pretendía laminar el poder que tenía la Iglesia en esta materia e ir asumiéndolo la Administración (Vidal, 1987: 43).

5 [<http://www.ub.edu/geocrit/sv-32.htm〉]. y la respuesta a la conflictividad y a la pobreza de la clase trabajadora, fue, entre otras, la creación de dicha comisión. Como señala De la Calle (1984), es el primer asomo de política social del Estado, y que con su desarrollo dio lugar, entre otros, a la creación del Instituto del Trabajo o el Instituto de Reformas Sociales (génesis del Instituto Nacional de Previsión).

Durante el primer tercio del Siglo XX hay señales del tránsito a la asistencia social. No sólo se crean los seguros sociales, sino que hay una transformación de la beneficencia aunque con visos de asistencialismo. De hecho, Matos y Raya (2012: 152) consideran que se mantenían las funciones de "represión de las clases y grupos empobrecidos y marginados".

Efectuando un salto temporal llegamos al franquismo. En la fase autárquica existe un sistema benéfico, donde la actuación quedaba en manos de la Iglesia católica y el "auxilio social" a Falange Española. Los primeros esbozos de intervención social asistencialista durante el franquismo tienen lugar con la creación por parte de Cáritas de la Sección Social en el año 1957 (Gutiérrez, 2001: 90), y posteriormente del sistema de seguridad social (1963). Ya a principios de los años setenta ${ }^{6}$ se crea el Plan Nacional de la Seguridad Social de atención a los ancianos. Esta orden recoge:

"[...] la ayuda a domicilio a los pensionistas que por su estado de salud la requieran, que podrá manifestarse en: el aseo personal y limpieza del hogar, lavado de ropa, asistencia médica a domicilio, servicio de comida, mejora del hogar, compañía a ancianos enfermos, terapia ocupacional, asistencia social, moral y jurídica, servicio de peluquería y biblioteca" (art. 2.5).

Este plan fue el germen del futuro Imserso, creado en 19787. Uno de los avances en estos primeros años democráticos fue que la ayuda a domicilio amplió sus destinatarios: no solo la tercera edad y los discapacitados físicos y psíquicos, sino también población con algunas dificultades.

Situándonos en la etapa democrática, en la Constitución de 1978 figuran los servicios sociales y la atención a la tercera edad. Es con la ley de leyes y con la constitución de los primeros ayuntamientos democráticos cuando tiene lugar la extensión del SAD (Revuelta, 2015: 114). En relación con la tercera edad, la Constitución de 1978 establece que "los poderes públicos [...] promoverán su bienestar [de la tercera edad] mediante un sistema de servicios sociales que atenderán a sus problemas específicos de salud, vivienda, cultura y ocio" (artículo 50). Al mismo tiempo, la asistencia social aparece como una de las competencias que pueden asumir las comunidades

\footnotetext{
${ }^{6}$ Orden de 26 de febrero de 1971, por la que se regula el Plan Nacional de la Seguridad Social de asistencia a los ancianos.

7 Real Decreto-Ley 38/1978, de 18 de noviembre sobre gestión institucional de la Seguridad Social. En su artículo 1.1.3 se crea el Instituto Nacional de Servicios Sociales (INSERSO).
} 
autónomas (artículo 148.20), competencia que finalmente será asumida por éstas en sus respectivos estatutos de autonomía.

Un hito importante relativo a los servicios sociales, y en particular al SAD, es la aprobación del Plan Concertado de Servicios Sociales de 1988. Sus pretensiones son las de universalizar los servicios sociales básicos, que sean de calidad, así como la construcción de red pública de equipamientos, y la cooperación con las corporaciones locales. En este plan se incluyen las prestaciones básicas, entre las cuales está la ayuda a domicilio y otros apoyos a la unidad de convivencia.

\subsection{Sobre el Servicio de Ayuda a Domicilio en la actualidad: definición, contenido y principales actividades que lo comprenden}

Llegados a este punto, pasamos a la definición y contenido del SAD. Según Rodríguez y Valdivieso (2006: 34) este servicio es:
"Un programa individualizado, de carácter preventivo y rehabilitador, en el que se articulan un conjunto de servicios y técnicas de intervención profesionales consistentes en atención personal, doméstica, de apoyo psicosocial y familiar y relaciones con el entorno, prestados en el domicilio de una persona mayor dependiente en algún grado".

Otra definición es la ofrecida por García Herrero (2010: 56) para quien:
"El servicio de ayuda a domicilio es un servicio social que deben garantizar las Administraciones Públicas, con el objetivo de procurar utilidades para que, en situaciones de necesidad, las personas puedan permanecer en sus propios domicilios con un adecuado nivel de calidad de vida, de manera que se refuercen su autonomía, la convivencia personal y las relaciones sociales".

Del mismo modo que hemos acudido a la literatura científica para dar la definición, podemos acudir a otras fuentes para conocer de qué significado se dota al SAD. En el Estatuto de Autonomía valenciano se recoge la competencia en materia de servicios sociales (art. 49.20). Asumida esta competencia, el gobierno valenciano sancionó la Ley 5/1997, reguladora del sistema de servicios sociales, arrogándose la competencia en servicios sociales y clasificándolos en generales y específicos. Dentro de los servicios sociales generales figura el SAD (art. 12), para la cual estamos ante un servicio para:

“[...] prestar atención de carácter doméstico, psicológico, rehabilitador, social, personal y educativo, cuando la situación individual o familiar sea de especial necesidad, procurando la permanencia de la persona en su núcleo familiar o de convivencia de origen".
Sobre las actividades que se incluyen en este servicio, y siguiendo a Rodríguez y Valdivieso (2006: 37), hay unos objetivos que cumple el SAD que, a su vez, se pueden traducir en actividades a desempeñar por las auxiliares de ayuda a domicilio. Estas vienen a cubrir aquellas tareas que no pueden ejecutar los usuarios, tales como las actividades básicas de la vida diaria (ABVD) - levantarse, acostarse, vestirse, realizarse el aseo personal, etc. $-y$ actividades instrumentales de la vida diaria (AIVD) -cocinar, limpiar, hacer compras, gestiones, control de la medicación, desplazarse por la calle, etc.-.

\subsection{La "bicefalia" en el SAD: SAD municipal y SAD derivado de la Ley de la Dependencia}

Si hasta el momento hemos atendido al SAD municipal, desde la aprobación de la Ley de la Dependencia emerge un nuevo tipo de servicio de ayuda domiciliaria. Es en esta ley donde se recoge un catálogo de servicios y prestaciones económicas, entre las que destacamos dos: por un lado, el SAD, y por otro, la prestación económica vinculada al servicio.

Respecto del primero, el artículo 22 de la citada ley establece que este servicio está formado por actuaciones que se efectúan en el domicilio de la persona dependiente para atender sus necesidades de la vida diaria, ejecutadas por una entidad acreditada para ello. Estas actuaciones pueden ser bien servicios relacionados con la atención personal, bien servicios relacionados con las necesidades domésticas o del hogar.

Por otra parte, nos encontramos con la prestación económica vinculada al servicio (art. 17). En este caso, al beneficiario se le otorga una prestación de tipo económico para la adquisición de un servicio, como puede ser el caso del servicio de ayuda domiciliaria. Y se concede en función del grado de dependencia que se le haya reconocido a la persona dependiente y de su capacidad económica. La cuantía de esta prestación depende de qué grado tiene reconocido la persona en situación de dependencia y, de este modo, la regulación actual establece que hay una cantidad y un intervalo de horas que recibirá el beneficiario, tal y como figura en la Tabla 1. Para esa cuantía de horas se concederá una prestación económica, que tiene la finalidad de adquirir en el mercado privado los servicios a los que no se puedan acceder con los recursos que hay en el sistema, es decir, serán los operadores privados quienes presten el servicio. En la actualidad, quedaría como figura en Tabla 1. No obstante, el SAD de la dependencia en el País Valenciano arroja cifras paupérrimas: en enero del 2018 solo hay 41 casos en los que se ha concedido este SAD, un exiguo o,6\% del total de prestaciones y servicios (según datos del Portal de la Dependencia). 
Tabla 1. Cuantía e intensidad horaria de la prestación económica vinculada al servicio ${ }^{8}$

\begin{tabular}{|l|c|c|}
\cline { 2 - 3 } \multicolumn{1}{c|}{} & $\begin{array}{c}\text { Cuantía prestación económica } \\
\text { vinculada al servicio }\end{array}$ & Intensidad horaria \\
\hline Grado III & 715,07 & $46-70$ horas al mes \\
\hline Grado II & 426,12 & $21-45$ horas al mes \\
\hline Grado I & 300,00 & $\begin{array}{c}\text { Máximo } 20 \text { horas } \\
\text { al mes }\end{array}$ \\
\hline
\end{tabular}

Fuente: Elaboración propia a partir de información de <[http://www. inclusio.gva.es/web/dependencia/cuantias〉].

\section{Resultados obtenidos a partir del trabajo de campo}

En este epígrafe se concentran los resultados obtenidos en el trabajo de campo tras la realización de las entrevistas a trabajadoras sociales de las corporaciones locales, a representantes de la patronal y sindicatos, a empresas prestadoras del SAD y a auxiliares de ayuda a domicilio.

\subsection{Procedimiento y requisitos a cumplir para la concesión del SAD municipal}

Las trabajadoras sociales de los servicios sociales de los ayuntamientos siguen un mismo procedimiento a la hora de conceder la ayuda domiciliaria. La regla general es que se parte de una cita previa del vecino del municipio con la trabajadora social en la que expone su situación. Las trabajadoras sociales realizan un examen inicial de la situación a partir de una entrevista personalizada y a partir de ella cuentan con una información que será la base para la posterior intervención. Es entonces cuando se valora qué actuación es la más adecuada, entre ellas la concesión del SAD. Posteriormente se realiza una segunda entrevista, en la que se presentará toda la documentación pertinente para la concesión del servicio: fundamentalmente informes médicos, situación familiar e información de cariz económico. Al procedimiento de carácter administrativo le sigue una visita domiciliaria para valorar qué actuaciones son las necesarias para el usuario. En caso de que el informe definitivo sea positivo y se conceda la ayuda domiciliaria, el siguiente paso es la activación del servicio. En cualquier caso, la decisión, finalmente, está motivada por un informe técnico de la trabajadora social municipal, hecho remarcado por la totalidad de las trabajadoras sociales entrevistadas (“la prescripción técnica siempre es del trabajador social, siempre”, trabajadora social, ayuntamiento_G; "como en todo de servicios sociales, siempre dejan luego el criterio de la trabajadora social [...] como en todos los reglamentos

${ }^{8}$ Antes de la reforma llevada a cabo en el año 2012, existían no solo los grados sino también dos niveles dentro de cada uno de ellos. En este caso, la intensidad horaria era la que sigue: Grado III, nivel 2: entre 56 y 70 horas/mes; Grado III, nivel 1: entre 46 y 55 horas/mes; Grado II, nivel 2: entre 31 y 45 horas/mes; Grado II, nivel 1: entre 21 y 30 horas/mes; Grado I, niveles 1 y 2 : máximo de 20 horas/mes. siempre ponen "a criterio del trabajador social", trabajadora social, ayuntamiento E).

“[...] presentar toda la documentación en el que consten aspectos médicos, sociales y económicos" (trabajadora social, ayuntamiento_A).

No obstante, y aunque el conocimiento de la situación o problema del vecino sea generalmente porque este acuda a los servicios sociales, también existen casos en los que la información proviene de agentes externos (por ejemplo, partes policiales 0 derivaciones desde los centros de salud) o por visita domiciliaria de la propia trabajadora social.

\subsection{Gratuidad o no del servicio}

Una de las cuestiones planteadas a las trabajadoras sociales entrevistadas estuvo relacionada con la gratuidad o no del SAD. Así, en algunos municipios como Valencia o Alboraia sí que existe el pago de una tasa o copago. En el caso de Alboraia se procede a una baremación de la situación del vecino del municipio y, en función del resultado obtenido, el usuario paga un porcentaje respecto del precio del servicio ("entonces se saca la puntuación y se saca lo que tienen que pagar", trabajadora social, ayuntamiento_C). Así, una parte la paga la Administración local y otra parte la abona el usuario. Esta situación es extensible al municipio de Valencia, en el que también se debe proceder al pago de una tasa, aunque de forma excepcional puede declararse la exención del pago por la situación de necesidad, todo y no cumplir con los requisitos.

\section{“[...] entonces la ayuda a domicilio se prioriza, porque no tenemos un presupuesto ilimitado, se prioriza a las personas solas sin hijos o familiares que puedan atenderlos. Entonces estas personas, según el nivel de renta, tendrían un copago de la hora de tanto según el nivel de renta" (trabajadora social, ayuntamiento J).}

En el resto de municipios analizados no hay pago de tasa alguna. Como manifiesta una persona entrevistada, o se concede el servicio porque cumple con los requisitos o no se concede, pero no existe el desembolso de cuantía alguna por recibir el servicio. Aquí entran en juego el montante existente en las arcas públicas municipales, las partidas presupuestarias designadas al SAD, y la voluntad política de cada corporación local.

"Y aquí por ejemplo no es con copago. Aquí es totalmente gratuito para el usuario. Lo que en otros municipios sí que tienen un pequeño copago" (trabajadora social, Ayuntamiento E)

“No, no hay copago. Es gratuito" (Trabajadora social, ayuntamiento I). 


\subsection{Perfil de los usuarios del SAD}

A las personas entrevistadas también se les preguntó acerca del perfil más generalizado de los usuarios del SAD. En este sentido todos respondieron que son personas mayores, del grupo perteneciente a la tercera edad, con problemas de salud y, de entre ellas, más mujeres que hombres. También aparece como otro común denominador que son personas con bajos ingresos monetarios. En esta respuesta coincidieron tanto las trabajadoras sociales como los responsables de entidades prestadoras del SAD y auxiliares de ayuda a domicilio entrevistadas.

“[...] normalmente suelen ser o matrimonios o personas solas con bajos ingresos y que no cuentan con el apoyo de los hijos. Entonces tienen unos problemas de salud, que ellos ven que ya tienen un deterioro que ya no pueden ducharse, arreglarse..." (trabajadora social, ayuntamiento J).

“[...] tenemos muchos casos de ancianos que están solos, los hijos trabajan y cobran una pensioncita razonable. Pensión, como todos... pues 600, 700 euros..." (trabajadora social, ayuntamiento $\mathrm{A}$ ).
No obstante, recalcan que hay otros tipos de SAD, como el educativo, dirigido para menores que necesitan una “organización” de su vida diaria

“[...] si son tareas con menores, por ejemplo, que vayan al colegio, que la mamá tenga preparada la ropita para el día siguiente, que hagan los deberes, que haya un horario en casas, que haya una distribución razonable de espacios, que la ropa esté plegada... ese tipo de cosas" (trabajadora social, ayuntamiento G).

\subsection{Modalidades en la prestación del SAD}

Las corporaciones locales estudiadas han optado por diferentes modalidades de prestación del servicio. Así, en los casos de Alboraia, Benetússer, Tavernes Blanques y Rocafort el servicio está municipalizado. Por tanto, el servicio es de titularidad y prestación/ provisión pública, y las auxiliares de ayuda a domicilio forman parte de la plantilla de la corporación. En algunos casos son funcionarias y en otros son personal laboral. Mientras, en Alaquàs, Paterna y Burjassot se han creado empresas públicas dedicadas a la gestión del SAD. En Alaquàs la empresa pública

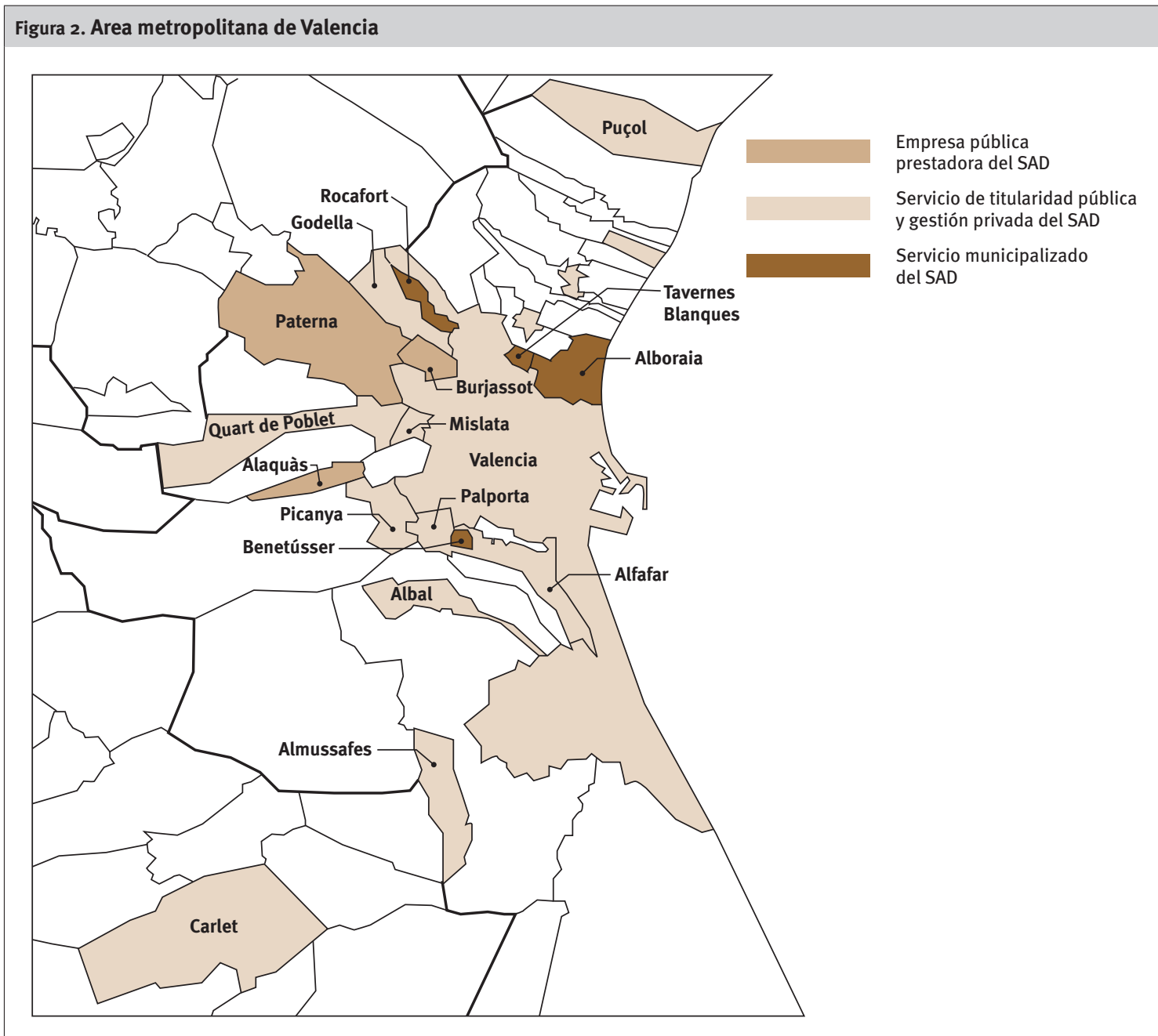

Fuente: Ghaleb Fansa. 
es Alem, en Paterna recibe el nombre de Gespa y en Burjassot, Cemef. En el resto de ayuntamientos estudiados el servicio está externalizado a una empresa privada. Son los casos de Albal, Valencia, Godella y Mislata, aunque no son los únicos. Así, y a partir de entrevistas a empresas que trabajan en el sector, otros municipios que también tienen externalizado el SAD son Alfafar, Almussafes, Carlet, Paiporta, Picanya, Quart de Poblet o Puçol (ver Mapa 1). El caso del municipio de Valencia, por su tamaño y población, es el que presenta una configuración distinta al resto de municipios analizados. La primera característica es el número de casos atendidos: 1.939 unidades familiares, cifra que contrasta de forma sobresaliente con el resto de municipios. Por otro lado, Valencia se encuentra dividida en tres lotes a la hora de prestar el SAD, tal y como figura en la licitación del servicio. Hasta la fecha de realización de las entrevistas, Valencia quedaba repartida entre tres empresas, y cada una de ellas tenía asignado un lote. Cada lote está formado por unos distritos municipales. Así, un lote tiene cuatro distritos, otro lote cuatro distritos y uno último, tres distritos. Y cada distrito tiene una coordinadora de la empresa prestataria. Las operadoras son las empresas GESMED, La Saleta, y la cooperativa SERCOVAL. Sin embargo, esta distribución está pendiente de modificación a raíz de la última licitación, la cual ya ha sido resuelta pero no se ha consumado?.

Junto a la modalidad escogida por cada corporación local se les preguntó acerca de los beneficios o inconvenientes que tiene un servicio externalizado y un servicio prestado directamente por el ayuntamiento.

En cuanto a las ventajas las trabajadoras sociales opinan que un servicio municipalizado tiene sus ventajas: consideran que es un servicio más económico para las arcas municipales y, sobre todo, que tiene sus ventajas en su dimensión laboral, pues las auxiliares de ayuda a domicilio de gestión y prestación/provisión pública tienen mejores condiciones laborales que las auxiliares de un servicio externalizado. Además, en algunas entrevistas la respuesta fue que los servicios sociales deberían ser públicos tanto en su titularidad como en su prestación/provisión. Una cuestión, por tanto, ideológica.

\begin{abstract}
“Pero sí que sale más económico, ¿eh? Sale más económico el tema de tener a las auxiliares en la empresa pública municipal; sale más barato que tenerlas en una empresa privada, por supuesto" (trabajadora social, ayuntamiento A).
\end{abstract}

Mientras, y sobre los inconvenientes de tener el servicio municipalizado, destacan que supone una sobrecarga de trabajo para la trabajadora social

\footnotetext{
9 Tras la última licitación, la empresa ganadora del concurso público fue Gesmed. Sin embargo, esta ha renunciado a uno de los lotes. El lote rechazado ha sido adjudicado a la empresa Sarquavitae, nueva en la prestación del SAD municipal en el Ayuntamiento de Valencia.
}

porque debe hacer las veces de trabajadora social de los servicios sociales generales más la coordinación del SAD.

No obstante, también es cierto que cuando se externaliza el servicio se pueden incluir en los pliegos algunos elementos que permitan mejorar la calidad. Así, en dichos pliegos se suele incluir un apartado destinado a "mejoras", que son propuestas que hace la empresa en beneficio del servicio y que son puntuadas por la Administración que licita el concurso. En este caso, las empresas sí que pueden aportar (y así consta en las entrevistas a empresas del sector y a los representantes de la patronal) algunos aspectos que repercuten en la calidad del servicio, como puede ser el caso de disponer de grúas para la movilización de los usuarios, algunas ayudas técnicas, disposición de plazas residenciales para casos de urgencia, etc. Como remarcan las empresas entrevistadas, esto repercute en la calidad del servicio, dado que la corporación local no cuenta con dichos recursos.

\subsection{Cómo se organiza y planifica un SAD}

La organización y planificación es idéntica tanto para el SAD municipalizado como para los casos de externalización del servicio. Así, existe una coordinadora que distribuye entre las auxiliares de ayuda a domicilio el trabajo a desempeñar. Para ello hace entrega de una planilla, en la que figuran los datos personales del usuario, la dirección, un número de teléfono, las actividades a desempeñar, el horario en el que debe ejecutarse su trabajo y observaciones que sean de interés para el desarrollo de su labor. Su entrega se hace o semanalmente o mensualmente. En ocasiones la planilla puede ser fruto de alguna modificación, en cuyo caso la coordinadora se lo comunicará o vía telefónica o mediante correo electrónico a la auxiliar de ayuda a domicilio. Por su parte, las auxiliares, conociendo el trabajo a realizar, harán la ruta asignada en función de lo fijado en la planilla. Por regla general, las coordinadoras tratan que todos los domicilios a los que tiene que acudir la auxiliar estén cercanos entre sí, a lo que denominan zonificación. Es decir, las auxiliares trabajan en un determinado distrito postal (caso de Valencia) o en una determinada zona del municipio, y dentro de estos, buscan cuadrar los domicilios dentro de un radio de actuación lo más restringido posible, con el fin de que los desplazamientos de una vivienda a otra sean lo más cortos posibles. Durante el transcurso de su trabajo pueden suceder algunos imprevistos o incluso que deba activarse el protocolo de emergencia, de ahí que se diga que las auxiliares son los ojos de las coordinadoras y de las trabajadoras sociales, tal y como señalan Torns et al. (2014: 80). En este caso, la auxiliar se pondrá en contacto vía telefónica con la coordinadora para comunicarle la incidencia. La coordinadora llamará al domicilio del usuario o usuaria y en el caso de no haber contestación se pondrán en contacto con algún familiar del usuario (si lo hubiere) para que se 
desplace hasta la vivienda de este para abrir y ver qué sucede. Si no abriese se activaría el protocolo de emergencia: la llamada al 112.

\subsection{El punto de vista de las empresas: caracterización y principales obstáculos para el desarrollo de su actividad}

El subsector del servicio de ayuda a domicilio está formado por 174 empresas que operan en el País Valenciano, según consta en el listado de empresas autorizadas por la conselleria correspondiente (vicepresidencia y Conselleria de Igualdad y Políticas Inclusivas). No obstante, y tras llamar telefónicamente a todas las empresas que operan dentro de los márgenes del área metropolitana de Valencia, nos hemos encontrado con dos situaciones. Una de ellas es que el listado no está actualizado, habiendo desaparecido una parte de estas, hecho corroborado por la misma patronal en la entrevista realizada. Otra es que hay empresas que están autorizadas pero no prestan el servicio porque no tienen casos que atender: activarán el servicio cuando exista demanda para ello. Si tuviésemos que caracterizar el sector, diríamos que está polarizado, con unas pocas empresas con un tamaño relativamente grande, de 100-150 trabajadores, y muchas otras de menor tamaño, muy localizadas y asentadas en el territorio. Al final, como declaran los representantes de la patronal, se trata de un servicio de proximidad, donde la cercanía es un factor relevante y decisivo para la elección por parte del usuario a la hora de escoger la empresa.

En el caso del SAD municipal, para el caso de la capital, Valencia, la prestación queda encomendada en favor de tres empresas (próximamente dos). En el resto de los municipios analizados es una sola empresa la que se encarga de la prestación del servicio de ayuda domiciliaria. Tanto en Valencia como en el resto de municipios hay una coordinación y comunicación fluida entre la trabajadora de los servicios sociales de base y la trabajadora social/ coordinadora de la entidad prestataria.

Cuestión aparte es la que se produce en el SAD derivado de la prestación económica vinculada al servicio propio de la Ley de la Dependencia o en un SAD privado, donde los usuarios tienen libertad de elección de la organización que le preste el servicio. Es decir, y para el primero de los supuestos, si se concede una prestación económica vinculada al servicio, el beneficiario recibirá una cuantía de dinero con la que contratará los servicios de una empresa de las que figuran en el listado de entidades autorizadas. En este supuesto, los usuarios tienen mayores posibilidades para la contratación, habida cuenta del número elevado de empresas. Ahora bien, para el caso de la prestación económica vinculada al servicio hay que resaltar que hay una ausencia de controles, tal y como relatan los representantes de los sindicatos más representativos, y que dicha ausencia afecta a la calidad del servicio.
“[...] el dinero se lo dan a la persona dependiente, esta contrata a una empresa, ese contrato se lo tiene que remitir a la conselleria, y todos los meses le tiene que remitir las facturas. ¡La conselleria no tiene personal para controlarlo! La mayoría no sabe si te mandan las facturas, y mucho menos el servicio que te prestan". [...] Lo fundamental es que en el SAD municipal existe una estabilidad en el empleo, unos mejores salarios, un control por parte de la administración y un control por parte de la empresa de la prestación del servicio. En la prestación vinculada al servicio, la administración no controla nada. Ni la facturación ni la empresa, ni si el servicio se presta bien o se presta mal" (representante de CC.00.-Pais Valencià).

Junto a esto, un representante de uno de los sindicatos declaró que un problema es que existe un listado de empresas autorizadas, pero no hay ninguna orden de acreditación donde se recojan los requisitos mínimos a cumplir por las empresas. Esto, obviamente, es una falta de garantía en cuanto a la calidad de un servicio ${ }^{10}$.

"El primer problema es que no hay orden de acreditación, por lo tanto, yo no tengo regulado cómo pueden acceder al servicio, ni qué criterios deben tener las empresas para entrar a prestar ese servicio. Porque en la orden de acreditación tiene que regular los trabajadores mínimos, las instalaciones mínimas, los servicios informáticos, el material que necesitas, los derechos del usuario, los deberes del usuario..." (representante de CC.00.-Pais Valencià).

Las empresas autorizadas, y según la información recibida a partir de las entrevistas realizadas, se encuentran con obstáculos o dificultades de diferente índole. Uno de ellos, relacionado con el SAD municipal, es que las corporaciones locales que sacan a concurso la prestación del SAD lo hacen con unos precios muy ajustados o incluso "a la baja”. Es decir, son concursos que salen con unos precios muy ajustados respecto a los costes totales del servicio, teniendo en cuenta que el grueso de los gastos que tiene una entidad prestadora del servicio son los costes laborales. Así, y según sus cálculos, un precio ajustado al coste del servicio estaría en torno a los 13 euros/hora, y hay ayuntamientos que han sacado a licitación concursos con cifras muy próximas a esta, o incluso, por debajo de esta cuantía. Esto ha llevado a que la patronal del sector haya tenido que recurrir en los tribunales algunos concursos porque con ello no estaban cubriéndose los propios gastos de su actividad. El hecho de establecer precios tan ajustados por parte de los ayuntamientos en sus concursos lleva consigo que el margen de beneficios de las empresas sea muy limitado, y manifiestan que esto va en perjuicio de las mismas trabajadoras, especialmente de las auxiliares de ayuda a domicilio.

${ }^{10}$ Pese a no existir tal orden de acreditación, la conselleria competente publica el listado como si fuesen empresas acreditadas. 
"[...] hay un tema que es gravísimo. Y es que hay concursos que salen por debajo del coste laboral. [...] no es que tengas mucho margen... no es que dijeras: tengo un margen del $20 \%$ con cada hora, tú puedes mejorar la retribución del trabajador reduciendo margen tuyo. Pero si es que si tú haces el cálculo de un servicio de ayuda a domicilio, solo los costes y los precios que hay, ¡se comen el margen! el margen es muy escaso..." (representante de la patronal Aerte).

En relación con el punto anterior, en los concursos se establece un número de horas que deben prestarse. Sin embargo, en determinadas temporadas hay aumentos de demanda que deben ser cubiertos con la contratación de más personal. Ahora bien, ese aumento es ocasional y, por tanto, posteriormente desaparece la demanda y vuelve a los niveles previos. Así, tienen un personal fijo más una personal contratado por circunstancias de la producción para esas épocas de mayor demanda.

Para el caso del AMV, las empresas no están teniendo problemas en cuanto al reclutamiento de personas para trabajar como auxiliares de ayuda a domicilio. Situación diferente ocurre en otros lugares más alejados, como zonas rurales, donde tienen que recurrir a agentes intermediarios para encontrar a este personal: se nos mencionan a las trabajadoras sociales de algunos ayuntamientos de áreas rurales, a agentes de desarrollo local y al Servicio Valenciano de Empleo (Servef). Esto es una muestra de la territorialización de los mercados de trabajo y cómo hay diferencias en los mercados locales de trabajo según se trate de zonas urbanas o zonas rurales.

“[...] el problema que nos encontramos nosotros es que en ciertos lugares, pueblos alejados de Valencia, hay problemas para encontrar a personas cualificadas" (responsable de empresa prestadora del SAD, empresa 1).

Una de las circunstancias actuales del SAD es la exigencia de que el personal de la entidad o las posibles candidatas a un puesto de auxiliar de ayuda a domicilio tengan el título formativo exigido por la ley o bien el certificado de profesionalidad, una reivindicación que viene de lejos. Esto se aleja de lo demandado en los inicios del SAD, allá por los años ochenta, tal y como constatan las personas fundadoras de la primera organización prestataria del SAD en Valencia. Actualmente se exige que tengan una formación específica en materia de cuidados, como puede ser la formación profesional de grado medio de Técnico en Atención a personas en situación de dependencia, o bien los certificados de profesionalidad de atención sociosanitaria a personas en el domicilio o el de atención sociosanitaria a personas dependientes en instituciones sociales ${ }^{11}$. Así, las auxiliares de

${ }^{11}$ Ambos certificados de profesionalidad se aprobaron a partir del Real Decreto $1379 / 2008$, de 1 de agosto, por el que se establecen dos certificados de profesionalidad de la familia profesional Servicios ayuda a domicilio que llevaban trabajando durante años en el servicio han tenido que convalidar su experiencia profesional para recibir el certificado de profesionalidad y poder continuar trabajando. Mientras, para las nuevas contrataciones las empresas ya están requiriendo que tengan el nivel formativo exigido legalmente. La principal ventaja es que se asegura que el personal que realiza las funciones de cuidado a una persona mayor o en situación de dependencia tiene una formación o una experiencia profesional acreditada, garantía de su profesionalidad.
“[...] las auxiliares, que son técnicas sociosanitarias, auxiliares de enfermería, auxiliares de geriatría o personas con el certificado de profesionalidad" (responsable de empresa prestadora del SAD, empresa 2 ).

\begin{abstract}
"Pero es verdad que nuestro sector ha ido evolucionando. Antes no se pedía nada para ser auxiliar de ayuda a domicilio y afortunadamente eso ha ido evolucionando con la entrada en vigor de la Ley de la Dependencia y cada vez se pide más. Y nosotros lo que hacemos es fomentar que nuestros trabajadores estén formados" (representante de Aerte).
\end{abstract}

Las empresas entrevistadas prestan su servicio en algún SAD municipal del AMV. Sin embargo también ofrecen SAD derivadas de la Ley de la Dependencia o servicios netamente privados, es decir, en los que no hay ninguna financiación de la Administración Pública a la persona mayor o dependiente. De hecho, así actúa el grueso de las empresas que figuran en el listado. Pues bien, aquí también nos relatan los obstáculos a los que se deben enfrentar. Uno de ellos guarda relación con la Administración autonómica (SAD de la dependencia), y es que la Conselleria de Igualdad y Políticas Inclusivas ha decidido apostar más por la concesión de la prestación por cuidados familiares porque es más económica para la hacienda pública. Es decir, en lugar de tender a una prestación profesional han optado por los cuidados en el entorno familiar, un cuidado no profesionalizado, hecho que también nos señalaban Díez y Elizalde para la región de Madrid (2015: 135). Y esta decisión no está motivada por la creencia de que los cuidados familiares sean los óptimos, sino porque son más baratos que la concesión de cualquier otro tipo de prestación económica o servicio catalogado dentro de la Ley de la Dependencia. A enero del 2018, la prestación económica por cuidados familiares en el País Valenciano ascendía a 33.668 beneficiarios, es decir, el $51,48 \%$ del total de prestaciones y servicios de la Ley de la Dependencia (datos del Portal de la Dependencia).

\section{"[...] en las resoluciones se está favoreciendo mucho el tema del cuidador no profesional en el domicilio" (empresa prestadora del SAD, empresa 3).}

socioculturales y a la comunidad que se incluyen en el Repertorio $\mathrm{Na}$ cional de Certificados de Profesionalidad. 
Otro obstáculo citado por las entidades es la economía sumergida, ejercida por cuidadoras remuneradas en el ámbito doméstico pero sin que exista una empresa de por medio. Estamos hablando de ese mercado formado en gran medida por personas de nacionalidad extranjera, fundamentalmente procedentes de Latinoamérica, y que ofrecen servicios mucho más económicos para las familias.

Además de la economía sumergida, también se cita la competencia desleal efectuada por algunas otras empresas del sector. Apuntan a que algunas no están aplicando correctamente los convenios colectivos y abonan salarios más bajos de los que deberían corresponder.

La carencia de demanda suficiente en el SAD es otro tema sacado a colación en las entrevistas. Se trata de un servicio con poca demanda, especialmente en el SAD de la dependencia y en el SAD privado, una característica propia de los nuevos yacimientos de empleo, que se "configuran como mercados incompletos o insatisfechos” (Martín y Palma, 1999), es decir, que requieren de una demanda efectiva para su funcionamiento (Banyuls et al., 2002: 13). Además, subrayan que la crisis económica ha afectado aún más, si cabe, a esta situación. Por una parte, con la citada crisis descendió el número de horas que sacaban a concurso los ayuntamientos, aunque es cierto que estas minoraciones no han sido elevadas, y de hecho han sido los garantes de que el servicio siguiese en funcionamiento, permitiendo el mantenimiento de puestos de trabajo y los cuidados a personas mayores. Por otra, la crisis se notó especialmente en el SAD de la dependencia y en el privado, con un sobresaliente descenso de la demanda. Y es que la crisis conllevó la pérdida de capacidad adquisitiva de las familias y decidieron solucionar la problemática prescindiendo de los servicios que tenían contratados y "refamiliarizando" sus cuidados. Junto a esto, los testigos privilegiados también resaltan la lentitud o incluso paralización en la resolución de expedientes por parte de la conselleria, afectando así a la demanda del SAD derivado de la Ley de la Dependencia.

Con todo lo dicho, una de las informantes clave de la patronal opina que la visión que tiene la Administración para con el SAD no es la adecuada. Es visto como un servicio "secundario" y que no goza del soporte suficiente, al tiempo que no ven expectativas de cambio por parte de la Administración autonómica. Si bien las Administraciones locales sí que han apostado por ofrecer este servicio, estando muy asentado en muchas de ellas, desde la Administración regional no parece que la situación vaya a tornarse.

“El SAD, con lo importante que es, es la 'niña fea'. Y lo tengo que decir, está abandonadísimo. Sí que le están dando mucha importancia al cuidador no profesional, etc., pero no están ni informándose del servicio ni lo conocen bien, ni hacen unos cambios que al final son necesarios en la sociedad que estamos. El SAD está como estaba y no hay previsión de cambiar" (representante de Aerte).

\subsection{Las auxiliares de ayuda a domicilio: tareas, perfil y condiciones laborales}

Las tareas que se llevan a cabo en un SAD vienen determinadas en el reglamento de cada municipio, aunque en algún caso excepcional no exista tal reglamentación. El grueso de las tareas lo componen los cuidados personales, como lavarse, peinarse, vestirse, preparación de alimentos, toma de medicamentos, etc. En algunos municipios se centran exclusivamente en este tipo de actuaciones, como puede ser el ejemplo de Tavernes Blanques. Mientras, otras corporaciones locales amplían estas actividades y comprenden otras como hacer la compra, acompañamientos a médicos o a la farmacia, paseos, organización de facturas, preparar el desayuno o la comida, o la limpieza doméstica. Del relato extraído de las personas entrevistadas parece que ha habido cambios desde los inicios de los SAD municipales, y es que antaño se centraban en exceso en tareas domésticas, como la limpieza, $y$, de un tiempo a esta parte, hay un vuelco en esta tendencia y se promueve más la atención personal y la promoción de la autonomía.

“El aseo personal, vestir, o sea, puede ser lavar o puede ser ducha, es decir, no todos los días tienen que duchar a la persona. Pero sí realizar un aseo personal, que es lavarle, el vestido, por ejemplo, hay gente a la que se le apoya en el tema del desayuno o de la comida... el hacer compras, te digo lo que más se suelen poner en marcha. El hacer compras, el acompañamiento, por ejemplo, por si tiene que ir al banco [...] hay gente que lo que se le hace es acompañamiento solamente, y tiene un par de días a la semana, entonces esos dos días la mujer aprovecha al banco, para ir a la farmacia, para ir a lo que sea...entonces, en vez de hacérselo, vas con ella. Y lo haces. Lo que más es higiene personal, acompañamientos, aseos, vestir o desvestir. Esas son las tareas que más se ponen en marcha" (trabajadora social, ayuntamiento C).

“[...] hacemos movilizaciones de enfermos, levantar a personas por la mañana, a personas que no se pueden levantar de la cama, movilizaciones de encamados, aseos personales tanto en la cama como duchas, tareas de atención al hogar, tareas domésticas, tareas de hacer comidas, hacer compras, acompañamientos a médicos, es que es todo lo que se te pueda ocurrir... servicio de despertador de menores, servicios educativos para madres sobrecargadas con hijos... mil cosas, todo lo que te se te puede ocurrir lo puede llegar a hacer una auxiliar... hombre, menos las cosas que por convenio no se hacen, lógicamente. Pero básicamente es eso, aseos personales, movilizaciones y servicios de comidas, de acompañamientos" (trabajadora social, ayuntamiento A). 
En lo referente al perfil más generalizado de las auxiliares de ayuda a domicilio, estamos ante un sector claramente feminizado, no en vano todas las auxiliares entrevistadas fueron mujeres autóctonas, ajustado a lo planteado por Roca Escoda en el municipio de Mataró (2017: 375). Sus edades rondaron entre los 35-55 años. En cuanto a la feminización, esto es coincidente con las declaraciones efectuadas por el resto de personas entrevistadas, tanto patronal y sindicatos, como empresas prestadoras de este servicio: para algunos de ellos el porcentaje rondaría el $80 \%$ de mujeres y el $20 \%$ de hombres. Mencionan la presencia de hombres trabajando como auxiliares pero se centran en tareas muy específicas, como pueden ser levantamientos o aquellas en las que se exige mayor esfuerzo físico. Además, todavía existe cierto reparo por parte de las usuarias (recordemos que hay más usuarias que usuarios) a que les realicen determinadas tareas relativas a la higiene personal. Esta feminización casa con la población ocupada en la actividad de servicios sociales sin alojamiento (CNAE 09, n. $\stackrel{0}{88}$ ), donde la tasa de feminización asciende a casi el $80 \%$ (ver Tabla 2). Y, al mismo tiempo, coincide con los datos de alumnos matriculados en el curso 2014-2015 (último con datos disponibles) en el grado medio de Técnico en Atención a Personas en Situación de Dependencia, donde para el total del Estado español encontramos que un $85 \%$ de los alumnos matriculados son mujeres. Si acaso optásemos por visualizar qué porcentaje de mujeres estuvieron matriculadas en el grado de Atención Sociosanitaria en el mismo curso 2014-2015, éste asciende al 87\%.

Tabla 2. Ocupados de 16 o más años según sexo y actividad del establecimiento a dos dígitos en el País Valenciano

\begin{tabular}{|l|c|c|c|c|}
\hline $\begin{array}{l}\text { Actividad del } \\
\text { establecimiento } \\
\text { a dos digitos } \\
\text { (CNAE o9) }\end{array}$ & Total & Hombre & Mujer & $\begin{array}{c}\text { Tasa de } \\
\text { feminización }\end{array}$ \\
\hline Total & 1.771 .025 & 971.645 & 799.380 & $45,14 \%$ \\
\hline $\begin{array}{l}88 \text { - Actividades } \\
\text { de servicios } \\
\text { sociales sin } \\
\text { alojamiento }\end{array}$ & 11.430 & 2.475 & 8.955 & $78,35 \%$ \\
\hline
\end{tabular}

Fuente: Censo de Población y Vivienda.

Las auxiliares de ayuda a domicilio suelen comenzar su jornada laboral a las 7,30-8,30 horas, siendo la más usual esta última. Su jornada se alarga normalmente hasta las 14 horas, aunque esto varía en función de la duración establecida en contrato. Es esta la más generalizada porque la gran mayoría de las auxiliares está contratada a tiempo parcial ${ }^{12}$,

${ }^{12}$ Según el artículo 12 del Estatuto de los Trabajadores, "el contrato de trabajo se entenderá celebrado a tiempo parcial cuando se haya acordado la prestación de servicios durante un número de horas al día, a la semana, al mes o al año, inferior a la jornada de trabajo de un trabajador a tiempo completo comparable. Se entenderá por 'trabajador a tiempo completo comparable' a un trabajador a tiempo completo de la misma empresa y centro de trabajo, con el mismo tipo de contrato de trabajo y que realice un trabajo idéntico o similar. Si en la empresa no hubiera ningún trabajador comparable a tiempo completo, se considerará la jornada a tiempo completo prevista en el convenio colectivo de aplicación o, en su defecto, la jornada máxima legal”. existiendo cierto consenso en que la duración suele rondar las 30 horas semanales. Su justificación viene dada porque en las primeras horas de la mañana tienen que cubrir más servicios, menos a partir de la media mañana, y volver a crecer a la hora de las comidas. Lo que lo justifica es esa menor demanda a media mañana.

“[...] en lugar de tener a cincuenta trabajadores a ocho horas, como eso no lo puedes hacer, pues tienes a lo mejor cien trabajadores a cuatro [horas]. Con lo cual, el trabajo parcial, por las características del servicio [...]" (representante de Aerte).

“La gran mayoría tienen contratos de $25 \mathrm{y}$ 30 horas semanales. Eso es el contrato más estándar en este sector. Un 80 \% más o menos" (responsable de empresa prestadora del SAD, empresa 4).

"Lo que pasa es que los contratos de ocho horas son muy pocos, son muy poquitos [...] la mayoría son de 30 horas" (representante de CC.00.-Pais Valencià).

“En el SAD [es] jornada parcial, a tiempo parcial. Algo así como tranquilamente un $85 \%-90 \%$ de los trabajadores. Son muy poquitos los que hay a jornada completa" (representante de UGT-Pais Valencià).

Tras la consulta a las empresas, el tipo de contrato elegido para las auxiliares de ayuda a domicilio de un SAD municipal externalizado responde a la gestión de la mano de obra de cada una de ellas. De esta manera, hay unas trabajadoras contratadas como indefinidas y otras como temporales, estas últimas para cubrir ciertas eventualidades o cubrir picos de demanda. Por citar dos ejemplos a modo comparativo, una de las organizaciones tiene la mitad de su plantilla como indefinida y la restante como temporal. Mientras, otra organización (cooperativa) presenta un porcentaje del $75 \%$ como personal indefinido y el $25 \%$ como temporal. En este sentido, los sindicatos consideran que se trata de un sector con una relativa alta estabilidad en el empleo, puesto que cerca del $80 \%$ de las auxiliares de ayuda a domicilio de un SAD municipal son indefinidas y el $20 \%$ restante son temporales.

De entre los aspectos más destacables en relación con las auxiliares de ayuda a domicilio hay que resaltar las diferencias salariales existentes entre los diferentes sistemas prestatarios. Por un lado veríamos las diferencias existentes entre un SAD externalizado (titularidad pública y prestación privada) y un SAD municipalizado. Para ello escogemos dos auxiliares de ayuda a domicilio de cada uno de estos sistemas: la primera de ellas, trabajando en un SAD de prestación privada, el salario mensual es de 1.190 euros netos al mes, pagas incluidas. Mientras, una auxiliar de ayuda a domicilio que forma parte de la corporación 
local cobra 1.100 euros al mes sin tener las pagas prorrateadas. Esto es, que si se le prorrateasen las pagas, le correspondería 1.283 euros netos. La diferencia salarial entre una y otra trabajadora es un $15 \%$ superior de las auxiliares de ayuda a domicilio municipalizadas. Y eso sin contar con que la jornada laboral presenta diferencias entre ambas. La trabajadora-auxiliar de ayuda a domicilio que es personal del ayuntamiento tiene una jornada de 37,5 horas semanales, mientras que la otra trabajadora (SAD externalizado) tiene una jornada de 40 horas semanales (eso sin contar que la gran mayoría está contratada a tiempo parcial).

Por otra parte, si realizamos la comparativa entre las auxiliares de ayuda a domicilio de un SAD externalizado (titularidad pública y prestación privada) y las auxiliares de un SAD de la dependencia o un SAD privado, también se manifiestan las diferencias salariales. $Y$ es que los convenios colectivos aplicables son diferentes ${ }^{13}$. Las auxiliares de ayuda a domicilio que trabajan para un SAD de titularidad pública y gestión privada tienen mejores condiciones laborales que las otras auxiliares citadas, en torno a un $22 \%$ de diferencia salarial ${ }^{14}$.

Los mismos sindicatos traen a colación estas diferencias entre unas y otras auxiliares.

"Para que nos entendamos tranquilamente, podría ser que una trabajadora del SAD a tiempo completo con este convenio [público-privado] podría estar cobrando 1.000 euros, y con este convenio [privado] 850 euros. Haciendo el mismo trabajo y los mismos servicios. Es entre un $10 \%-15 \%$. Si es a media jornada sería 500 y 400 euros, ique para el caso es lo mismo!" (representante de UGT-Pais Valencià).

Esas diferencias quedarían reflejadas en la Tabla 3, donde se recoge el salario del convenio colectivo para el SAD de titularidad pública y gestión privada, y el convenio colectivo para el SAD de la dependencia.

${ }^{13}$ Para los contratos de titularidad pública y gestión privada se aplica el convenio colectivo para las empresas que tengan adjudicada mediante contrato con alguna Administración Pública la gestión de residencias de tercera edad, servicios de atención a las personas dependientes y desarrollo de la promoción de la autonomía personal, centros de día, centros Mujer 24 horas, centros de acogida y servicio de ayuda a domicilio, de titularidad pública y gestión privada en la Comunidad Valenciana. Para las auxiliares de ayuda a domicilio que prestan sus servicios en el SAD de la dependencia es aplicable el VI Convenio Marco Estatal de servicios de atención a las personas dependientes y desarrollo de la promoción de la autonomía personal.

${ }^{14}$ Una nota a destacar es que con los nuevos yacimientos de empleo no solo hay que ver la capacidad de generación de puestos de trabajo, sino también ahondar en su vertiente cualitativa, ver qué tipo de empleo y sus condiciones laborales (Banyuls et al., 2002: 5), pues comportan altos niveles de precariedad.
Tabla 3. Salarios SAD titularidad pública-gestión privada y SAD dependencia

\begin{tabular}{|l|l|}
\hline $\begin{array}{l}\text { SAD titularidad pública-gestión } \\
\text { privada }\end{array}$ & SAD dependencia \\
\hline 16.483 euros anuales bruto & 13.261 euros anuales bruto \\
\hline 9.24 euros/hora bruto & 7.56 euros/hora bruto \\
\hline 7.29 euros/hora neto & 5.95 euros/hora neto \\
\hline
\end{tabular}

Fuente: Elaboración propia.

Por tanto, estas diferencias existentes entre auxiliares de ayuda a domicilio realizando las mismas funciones, nos hace pensar en la existencia de una segmentación en este subsector del mercado de trabajo.

No obstante lo dicho sobre el salario de las auxiliares sujetas al convenio público-privado, tanto la patronal como los sindicatos nos indican que se han hecho esfuerzos muy notables para su incremento. Así, en los convenios para periodos temporales previos el salario era todavía menor, y a partir del 2006 se pactaron subidas anuales elevadas. Según los actores sociales y económicos, eran conscientes de que el salario era ínfimo para las actividades que debían desarrollar las auxiliares y decidieron incrementarlos. De esta forma se conseguía aumentar la fidelización de las trabajadoras, dado que existía mucho abandono del puesto en cuanto encontraban otro trabajo. Otra idea que subyace a lo aquí planteado es que el mercado de trabajo está sujeto a elementos estructurales, tales como la negociación colectiva. Además, y a partir de enero del año 2018, se ha acordado el incremento del salario de las auxiliares de ayuda a domicilio al cobrar conforme a la categoría de auxiliar de enfermería. Su justificación viene dada porque se trata de personal al que se le exige una cualificación profesional y, además, supondrá un mayor grado de reconocimiento de su labor: una manera de favorecer su visibilidad.

Otro de los aspectos destacables tras las entrevistas es el relativo al componente emocional de este trabajo. Las auxiliares entrevistadas manifiestan que se generan unos vínculos de cariño con las personas cuidadas, así como que echan en falta su pérdida cuando estos fallecen o dejan de recibir el servicio (por ejemplo, porque se han marchado a una residencia). Tratan de separar la labor del trabajo de los afectos, sin embargo, como relatan, “están trabajando con personas", por lo que los afectos y el cariño quedan incluidos dentro del desarrollo de su labor o trabajo. Sin embargo, sí que mencionan que tratan de no llevarse esos sentimientos a casa porque de lo contrario podría afectarles psicológicamente Esto coincide con el estudio de caso del municipio de Mataró al que hace referencia Roca Estrada (2017: 383), y que dice que "se ha de saber dónde comienzan y acaban sus funciones [las del auxiliar de ayuda a domicilio]". En este sentido, este punto es sacado a colación tanto las empresas prestatarias entrevistadas como los representantes sindicales y de la patronal, subrayando la importante 
carga emocional de este trabajo y la necesidad de separar trabajo y cariño.

\section{8. ¿Qué valoración tiene este trabajo para los usuarios y para la sociedad?}

Todas las personas entrevistadas consideran que los usuarios tienen una muy buena valoración del servicio. Para el caso de las empresas, hay que tener en cuenta que realizan controles de calidad del servicio anualmente, con lo que tienen constancia de la valoración por parte de los usuarios y qué aspectos deben mejorarse. Las auxiliares de ayuda a domicilio también coinciden en esta opinión: de hecho, los usuarios muestran su gratitud hacia ellas por la labor que (les) realizan.

En cuanto a la percepción de este trabajo por la sociedad, los sindicatos recalcan que no es un servicio suficientemente reconocido, y apuntan que sigue viéndose como "la empleada doméstica, la que viene a limpiar la casa” (representante de UGT-Pais Valencià). Es decir, hay una imagen distorsionada sobre el servicio. Entre las auxiliares de ayuda a domicilio hay opiniones contrapuestas. Algunas de ellas sí que creen que la sociedad valora positivamente su trabajo, mientras que otras creen que son vistas como personas con un bajo nivel formativo e, incluso, de una clase social baja y con escasa valoración social de su trabajo. Lo cierto es que lo dicho debe ligarse con otra de las preguntas que se les formulaba a las personas entrevistadas: si el SAD era conocido por la población. La respuesta es que creen que todavía no hay suficiente conocimiento acerca de este servicio y del trabajo que desempeñan las auxiliares de ayuda a domicilio, y que deberían hacerse esfuerzos para su visibilización $\mathrm{n}^{15}$.

“¿Sabes cuál es el principal problema de estas trabajadoras? Que no están reconocidas, no están reconocidas porque el SAD es un servicio profesional [...] es un oficio muy poco reconocido por la sociedad y por los propios usuarios" (representante de UGT-Pais Valencià).

"La gente lo desconoce [...] para la gente esto es 'la limpiadora que le paga la Seguridad Social'. No conocen el servicio [...] son las chicas de la Seguridad Social. Y la sociedad en general no lo conoce" (representante de CC.00.-Pais Valencia).

\section{Conclusiones}

A partir de la información recabada en las entrevistas en profundidad efectuadas podemos corroborar las hipótesis de partida de nuestro trabajo. En primer lugar, se muestran diferentes sistemas de

${ }^{15}$ En este sentido, el Ayuntamiento de Valencia, durante el último año, ha puesto en marcha una campaña informativa sobre el SAD en centros médicos de atención primaria y en centros para personas mayores. prestación del SAD, dado que en algunos casos está municipalizado, bien con personal propio, bien con la creación de una empresa pública, y en otros se externaliza en favor de empresas privadas. En segundo lugar, las actividades que conforman el servicio son prácticamente idénticas: levantamientos, aseo, higiene personal, acompañamientos, etc., con ligeras diferencias según del municipio que se trate. Algo similar ocurre con la intensidad horaria de los servicios, siendo una hora la intensidad mayoritaria, situación que provoca que el SAD sea un mero apoyo y tenga que compatibilizarse con otros tipos de cuidados.

Los servicios sociales de base son la puerta de entrada a este servicio, jugando un papel protagonista sus trabajadoras sociales. Son las encargadas de valorar si un vecino de su localidad cumple con los requisitos para ser usuario del SAD. Para ello tomarán en consideración aspectos médicos, sociales y económicos, aunque siempre quedará supeditada la decisión final al juicio profesional de la trabajadora social. Si cumplen con los requisitos y con el informe favorable de la trabajadora social, se activará el servicio, que es mayoritariamente gratuito.

En los casos en que el servicio esté externalizado, las empresas manifiestan algunos obstáculos, especialmente que los concursos suelen publicarse con unos precios muy ajustados a los costes del servicio. Además, desde una visión global del SAD, que incluye el SAD de la dependencia y el SAD privado, destacan como principales problemas la escasa demanda, la existencia de la economía sumergida, ejercida fundamentalmente por mujeres latinoamericanas, y la competencia desleal de algunas otras empresas, que aplican incorrectamente el convenio y abonan salarios inferiores. Además, la Administración autonómica no parece darle el peso y la atención que merece, habida cuenta de que han apostado por la prestación a los cuidadores familiares y no en la prestación económica vinculada al servicio, una visión alejada de la profesionalización del cuidado.

Puede afirmarse que las tareas que conforman el SAD estarían englobadas dentro de lo que se denomina "trabajo de cuidados", al incluirse actividades como el aseo personal, levantamientos, compras o limpieza doméstica, y en el que también va parejo un componente relacional y emocional.

En cuanto a las auxiliares de ayuda a domicilio, debemos establecer diferencias según varios aspectos: si se trata de personal propio o contratado del ayuntamiento o si se trata de un servicio externalizado; y si estamos ante un SAD municipal externalizado o un SAD derivado de la Ley de la Dependencia o un SAD privado. En primer lugar, vemos que las auxiliares de ayuda a domicilio que forman parte del personal del ayuntamiento, sea como funcionarias o sea como personal contratado, gozan de unas mejores condiciones laborales/ 
salariales que aquellas que prestan sus servicios para un SAD con empresa externalizada. Por otra parte, si diferenciamos las que efectúan su trabajo en un SAD municipal externalizado con las que lo prestan en un SAD derivado de la Ley de Dependencia o en un SAD privado, también observamos que las primeras tienen mejores condiciones laborales que las segundas. En cuanto a las primeras (SAD externalizado), sus jornadas suelen ser de 8 a 14 horas, dado que la gran mayoría está contratada a tiempo parcial, siendo la mayoritaria la jornada de 29-30 horas semanales. El tipo de contrato más usual es el indefinido aunque las empresas deben contar con bolsas de temporalidad para ajustarse a la demanda. No obstante, la temporalidad no es acusada gracias a que los pliegos de condiciones publicados por los ayuntamientos fijan unas horas a cubrir al año, facilitando las previsiones sobre el porcentaje de personal indefinido y temporal. El salario es un aspecto central en sus condiciones laborales: dado que la mayoría está contratada a tiempo parcial, su salario suele rondar los 800 euros. Tanto su salario como las jornadas a tiempo parcial nos lleva a pensar en la precariedad en sus condiciones laborales. Mientras, y en cuanto a las segundas, sus jornadas también son a tiempo parcial, el tipo de contrato el de obra o servicio determinado (hasta que finalice el cuidado) y su salario es un $22 \%$ inferior a las anteriores auxiliares. Así pues, en un mismo puesto de trabajo, el de auxiliar de ayuda a domicilio, hay una estratificación o segmentación del mercado laboral de las auxiliares de ayuda a domicilio, al encontrar diferentes condiciones laborales para un mismo puesto de trabajo, con mejores condiciones para las trabajadoras de un SAD público.

En suma, nos hallamos ante un servicio de apoyo en los cuidados a personas mayores o en situación de dependencia que favorece tanto a los receptores de cuidados como a sus familias. Sin embargo, y pese a la importancia que tiene para sus beneficiarios, no goza ni de suficiente valoración social ni las auxiliares de ayuda a domicilio se ven recompensadas con unas buenas condiciones salariales. 


\section{Bibliografía referenciada}

ALBORAIA. Reglamento regulador del servicio de ayuda a domicilio. 30 de julio 2012. http://www. alboraya.org/es_ES/web/tu-ayuntamiento/ detalle-normativa-municipal?groupld=10643\&a rticleld $=25530$

ALONSO, J.M. y GONZALO, B. (2000): La asistencia social y los servicios sociales en España, Madrid, Ministerio de la Presidencia, Boletín Oficial del Estado.

BANYULS, J.; CANO, E.; PITXER I CAMPOS, J. V. y SÁNCHEZ, A. (2002): "Condicions de treball en el nous jaciments d'ocupació", Quaderns de Ciències

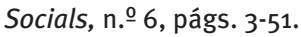

BETTIO, F. y PLANTENGA, J. (2004): "Comparing Care Regimes in Europe”, Feminist Economics, Vol. 10(1), págs. 85-113.

BETTIO, F.; SIMMONAZI, A. y VILLA P. (2006): "Change in care regimes and female inmigration: the 'care drain' in the Mediterranean", Journal of European Social Policy, n. $\stackrel{0}{16}$, 3, págs. 271-285.

BUJ, A. (1994). “La cuestión urbana en los informes de la Comisión de Reformas Sociales”. Scripta Vetera. Edición electrónica de trabajos publicados sobre Geografía y Ciencias Sociales. Reproducido de Horacio Capel, José María López Piñero y José Pardo (coords.): Ciencia e ideología en la Ciudad (III). I Coloquio Interdepartamental. Valencia. 1991, Valencia, Generalitat Valenciana/ Consellería d’Obres Públiques, Urbanisme i Transports, 1994, págs. 73-86. [<http://www. ub.edu/geocrit/sv-32.htm〉].

CARRASCO, C. (2003): “¿Conciliación? No, gracias. Hacia una nueva organización social" en Malabaristas de la vida. Mujeres, tiempos y trabajos, Grupo Dones i Treballs de Ca la Dona, Barcelona, Icaria.
CARRASCO, C.; BORDERÍAS, C. y TORNS, T. (2011): “El trabajo de cuidados: antecedentes históricos y debates actuales" en El trabajo de cuidados. Historia, teoría y políticas. Madrid, Los libros de la Catarata.

CARRASQUER, P. (2013): “El redescubrimiento del trabajo de cuidados: algunas reflexiones desde la sociología", Cuadernos de Relaciones Laborales, vol. 31, n. 1, págs. 91-113. [khttp:// revistas.ucm.es/index.php/CRLA/article/ view/41633/3969>].

CARRASQUER, P.; TORNS, T.; TEJERO, E. y ROMERO, A. (1998). “El trabajo reproductivo", Papers, 55, págs. 95-114.

CERRI, C. y ALAMILLO-MARTÍNEZ, L. (2012): “La organización social de los cuidados, más allá de la dicotomía entre esfera pública y esfera privada", Gazeta de Antropología, 28(2). [<http://www.gazetaantropologia.es $/ ? \mathrm{p}=4145>$.

COMAS D’ARGEMIR, D. (1993): “Sobre el apoyo y el cuidado. División del trabajo, género y parentesco", en ROIGÉ I VENTURA, X. (coord.): Perspectivas en el estudio del parentesco y la familia, Actas del VI Congreso de Antropología, Tenerife.

- (1995): Trabajo, género y cultura, Barcelona, Icaria.

- (2015): "Los cuidados de larga duración y el cuarto pilar del sistema de bienestar", Revista de Antropología Social, n. $\stackrel{0}{24}$, págs. 375-404.

- (2016): “Hombres cuidadores: Barreras de género y modelos emergentes", Psicoperspectivas. Individuo y Sociedad. Vol. 15, n.우 3, págs. 10-22. [«http://www.psicoperspectivas.cl/index.php/ psicoperspectivas/article/view/750〉].

COMUNIDAD VALENCIANA (2013): Conselleria de Economía, Industria, Turismo y Empleo Resolución de 10 
de enero de 2013, de la Subdirección General de Relaciones Laborales de la Dirección General de Trabajo, Cooperativismo y Economía Social, por la que se dispone el registro y publicación del texto del convenio colectivo para las empresas que tengan adjudicada mediante contrato con alguna administración pública, la gestión de residencias de tercera edad, centros de día, residencias materno-infantiles y servicio de ayuda a domicilio de titularidad pública en la Comunitat Valenciana.

- (2006): Ley Orgánica 1/2006, de 10 de abril, de Reforma de Ley Orgánica 5/1982, de 1 de julio, de Estatuto de Autonomía de la Comunidad Valenciana.

DALY, M. y LEWIS, J. (2000): "The concept of social care and the analysis of contemporany welfare states", British Journal of Sociology, vol. 51, n.ํㅜ 2, págs. 281-298.

DE LA CALLE, M.D. (1984): “La Comisión de Reformas Sociales: de la represión al análisis de la conflictividad social", Studia histórica. Historia contemporánea, $\mathrm{n} . \stackrel{0}{2}$, págs. $13-40$.

DE SÃO, J. (2016): "What are we talking about when we talk about care? A conceptual review of the literature", Sociologia, Problemas e Práticas, 81 , págs. 57-74.

DÍAZ, M. y ELIZALDE, B. (2015): “Desprofesionalizando el servicio público de asistencia a domicilio en los cuidados de larga duración: análisis de la reconfiguración del sector en la región de Madrid", Zerbitzuan, n. ㅇ, págs. 131-141.

EZQUERRA, S. (2011): "Crisis de los cuidados y crisis sistémica: la reproducción como pilar de la economía llamada real", Investigaciones feministas, vol. 2, págs. 175-194.

- (2018): “¿Qué hacer con los cuidados? De la Economía feminista a la democratización de los cuidados", Viento Sur, n. ${ }^{\circ}$ 156, págs. 39-47.

GARCÍA-MAESTRO, M.J. (2013): El régimen jurídico de la intervención administrativa en favor de la tercera edad. Especial referencia al servicio de ayuda a domicilio, Universidad de Salamanca (tesis doctoral).

GRAHAM, H. (1983): “Caring: a labour of love” en FINCH, JANET y GROVES: A Labour of Love. Women, Work and Caring, Londres, Routledge \& Kegan Paul, págs. 13-30.

GRAHAM, H. (1991). "The Concept of Caring in Feminist Research: The Case of Domestic Service", Sociology, 25(1), págs. 61-78.

GUTIÉRREZ, A. (2001): “El Plan Concertado de Prestaciones Básicas de Servicios Sociales en España (Once Años del Plan Concertado). REIS. Revista Española de Investigaciones Sociológicas, $\mathrm{n}$. 으 93, págs. 89-132.

HERRERO, G. (2011): "El servicio de ayuda a domicilio en la encrucijada”, Zerbitzuan, n.ํㅜ 49, págs. 55-70.

KNIJN, T. y KREMER, M. (1997): “Gender and Caring. Dimension of Welfare States: Toward Inclusive Citizenship", Social Politics, 4(3), págs. 328-361.

LEIRA, A. (1994): "Concepts of Caring: Loving, Thinking, and Doing”, Social Service Review, 68, 2, págs.185201.
LÓPEZ, F. (2010): “El buen samaritano no sabía de economía política: de la primera ley de beneficencia al intervencionismo científico (1822-1920)", Revista de la historia de la economía y de la empresa, n.. 4, págs. 21-45.

MARTíN, J.L. y PALMA, L. (1999): “"'Los nuevos yacimientos y la creación de empleo en la economía andaluza: implicaciones para los mercados de trabajo locales". Trabajo, n.ํㅜ 5-6, págs. 29-42.

MARTÍN PALOMO, M.T. (2008a): "Domesticar el trabajo: una reflexión a partir de los cuidados", Cuadernos de Relaciones Laborales, 26(2), págs. 13-44. [rhttp://revistas.ucm.es/index.php/CRLA/ article/view/CRLA0808220013A/32254'].

- (2008b): "Los cuidados y las mujeres en las familias". Política y Sociedad, vol. 45, n. 2, págs.29-47. [rhttp://revistas.ucm.es/index.php/POSO/ article/view/POSO0808230029A/22027)].

- (2014): Los cuidados en las familias. Un estudio a través de tres generaciones de mujeres en Andalucía, Madrid, Universidad Carlos III (tesis doctoral).

- (2016): Cuidado, vulnerabilidad e interdependencias. Nuevos retos políticos, Madrid, Centro de Estudios Políticos y Constitucionales.

MARTÍNEZ BUJÁN, R. (2010): Bienestar y cuidados: el oficio del cariño. Mujeres inmigrantes y mayores nativos, Madrid, CSIC.

MARTÍNEZ BUJÁN, R. y MARTÍNEZ VIRTO, L. (2015): "Conclusión. Propuestas para construir un modelo de gestión de los cuidados de larga duración basado en la equidad social, la igualdad de género y la cohesión territorial, Zerbitzuan, n. ㅇ, págs. 195-198.

MARTÍNEZ, F (sin fecha): “Los servicios de atención a domicilio en España: Antecedentes, Evolución Histórica y Marco Normativo", [<http:// docplayer.es/8398349-1-los-servicios-deatencion-a-domicilio-en-espana-antecedentesevolucion-historica-y-marco-normativo.htmls]..

MARUGÁN, B. (2014): “El trabajo de cuidados”, Eunomía, Revista en Cultura de la Legalidad, n. 7, págs. 215-223.

MUÑOZ GONZÁLEZ, Ó. y PITXER I CAMPOS, J.V. (2016a): “LoS cuidados en un contexto de crisis económica", Inguruak, n.으, 6o, págs. 102-121.

- (2016b): “La aplicación de la Ley de la Dependencia en el País Valenciano y su vínculo con el Estado del Bienestar: valoraciones a partir del caso del área metropolitana de Valencia", Zerbitzuan, n. 062 , págs. 67-84.

PARELLA, S. (2003): Mujer, inmigrante y trabajadora: la triple discriminación, Barcelona, Anthropos.

PATERNA (2015): Ordenança Reguladora de la Prestació del Servei d`Ajuda a Domicili, 30 setembre 2015.

PETERSON, E. (2015): “Framing caregiving work for older people in Spanish public policy: gender, power and social justice", Revista Española de Ciencia Política, núm. 39, págs. 221-237.

RAZAVI, S. (2007): The Political and Social Economy of Care in a Development Context: Conceptual Issues, Research Questions and Policy Options, serie "Programa Género y Desarrollo", n.ํㅜ 3, Ginebra, Instituto de Investigaciones de las Naciones Unidas para el Desarrollo Social. 
RECIO, C.; MORENO-COLOM, S.; BORRÀS, V. y TORNS, T. (2015): "La profesionalización del sector de los cuidados”, Zerbitzuan, n,으 60, págs. 179-193.

REVUELTA, M.L. (2015): "La ayuda a domicilio como servicio de proximidad en el contexto actual", Humanismo y Trabajo Social, n.ำ15, págs. 111-138.

ROCA, M. (2017): “Tensiones y ambivalencias durante el trabajo de cuidados. Estudio de caso de un Servicio de Ayuda a Domicilio en la provincia de Barcelona". Cuadernos de Relaciones Laborales, 35(2), págs. 371-391.

RODRÍGUEZ P. y VALDIVIESO C. (coords.) (2006): LoS servicios de ayuda a domicilio. Planificación y gestión de casos. Manual de formación para auxiliares, Madrid, Editorial Médica Panamericana.

SÁNCHEZ MARÍN, Á.L. (2014): "El instituto de reformas sociales: origen, evolución y funcionamiento", Revista Crítica de Historia de las Relaciones Laborales y de la Política Social, n.․․ 8, págs. 7-28. [<http://www.eumed.net/rev/ historia/08/reformas-sociales.htmls].

THOMAS, C. (2011): "Deconstruyendo el concepto de cuidados" en CARRASCO, C; BORDERÍAS, C y TORNS, T. (eds.). El trabajo de cuidados. Historia, teoría y políticas, Madrid, Los Libros de la Catarata, págs. 145-176.

TOBIO, C.; AGULLÓ, M.S.; GÓMEZ, M.V. y MARTÍN PALOMO M.T. (2010): El cuidado de las personas. Un reto para el siglo XXI, Colección Estudios Sociales, n. 을, Barcelona, Fundación Obra Social La Caixa.

TORNS, T. (dir), BORRÀS, V., MORENO, S. y RECIO, C. (2014): Nuevas profesiones para la organización social del cuidado. [khttp://www.inmujer.gob.es/ areasTematicas/estudios/estudioslinea2014/ docs/Nuevas_profesiones_organizacion_ social.pdf >].

TRONTO, J. (2005): "Cuando la ciudadanía se cuida: una paradoja neoliberal del bienestar y la desigualdad" en Congreso Internacional SARE 2004 ¿Hacia qué modelo de ciudadanía?, pp. 231-253, Vitoria, Emakunde.

UNGERSON, C. (2005): “Care, work and feeling”, The Sociological Review, vol. 53(2), págs. 188-203.

VIDAL, F. (1987): "El impacto de la Ley General de Beneficencia de 1822 en Madrid", Revista de la Facultad de Geografía e Historia, n. ${ }^{1}$, págs. 41-56. 